\title{
An in-depth analysis of young people's experience of their juvenile idiopathic arthritis (JIA) once receiving Etanercept P Livermore $^{* 1}, \mathrm{P} \mathrm{Woo}^{1}$ and LR Wedderburn ${ }^{2}$
}

Address: ${ }^{1}$ Great Ormond Street Children's Hospital, London, UK and ${ }^{2}$ Institute of Child Health, UCL, London, UK

* Corresponding author

\author{
from $15^{\text {th }}$ Paediatric Rheumatology European Society (PreS) Congress \\ London, UK. 14-17 September 2008 \\ Published: 15 September 2008 \\ Pediatric Rheumatology 2008, 6(Suppl I):PI64 doi:I0.II86/I546-0096-6-SI-PI64
}

This abstract is available from: http://www.ped-rheum.com/content/6/SI/PI64

(C) 2008 Livermore et al; licensee BioMed Central Ltd.

\section{Background}

At our institution a biologics clinic has been established to see specifically those children with JIA on anti-TNF treatment. It was through regular contact with these patients that it became apparent that some of these patients have difficult thoughts and concerns about biological therapies that are not being acknowledged fully. Little is published about the psychological responses of young people with JIA to success or failure of treatment and how they influence attitudes to future treatments.

\section{Methods}

An Interpretive Hermenutic Phenomenological approach was used to allow in-depth examinations of the young people's personal accounts of their lived experiences. Data was obtained from 6 individuals (aged 10-14 yrs) with JIA, receiving anti-TNF therapy during a routine clinic appointment using audio-taped unstructured interviews aided by spider diagrams. The interviews were carried out with informed consent, after ethical approval was given. The data were analysed using Colazzi's method.

\section{Results}

Overall response as either positive or negative, hinged on perceived success of their biologic therapy and interestingly on their relationships with school friends.

\section{Conclusion}

This study will assist in providing these patients with a better package of care, by providing the clinician with a deeper insight into how young people view their biologic treatments. As one individual said "Enbrel is useless cus it doesn't work for me. I don't get a say in anything. They pretend you do, but you still have to take the things. It's my body, but when I say I don't want it, they say I have to have it". 